\title{
Adjusting for Publication Bias Reveals Mixed Evidence for the Impact of Cash Transfers on Subjective Well-Being and Mental Health
}

\author{
František Bartoš ${ }^{1, *}$ Maximilian Maier ${ }^{2, *}$, T. D. Stanley ${ }^{3,4}$, Eric-Jan Wagenmakers ${ }^{1}$ \\ * Both authors contributed equally \\ ${ }^{1}$ Department of Psychological Methods, University of Amsterdam \\ ${ }^{2}$ Department of Experimental Psychology, University College London \\ ${ }^{3}$ Deakin Laboratory for the Meta-Analysis of Research (DeLMAR), Deakin University \\ ${ }^{4}$ Department of Economics, Deakin University
}

Correspondence concerning this article should be addressed to: František Bartoš,

University of Amsterdam, Department of Psychological Methods, Nieuwe Achtergracht 129-B, 1018 VZ, Amsterdam, The Netherlands f.bartos96@gmail.com

\section{Word count: 965}

Cash transfers are among the most popular poverty interventions. Indeed the charity evaluator GiveWell even lists GiveDirectly - a charity that directly sends your donations as cash to people in extreme poverty - as one of their top-rated charities [https://www.givewell.org/charities/give-directly]. McGuire, Kaiser, and Bach-Mortensen ${ }^{1}$ conducted a timely and comprehensive meta-analysis on the impact of cash transfers on subjective well-being and mental health, featuring 45 studies with a combined total of 116,999 individuals. McGuire and colleagues ${ }^{1}$ conclude "CTs [cash transfers] have a small but statistically significant positive effect on both SWB [subjective well-being] (Cohen's $\mathrm{d}=$ $0.13,95 \%$ confidence interval (CI) $0.09,0.18)$ and $\mathrm{MH}$ [mental health] ( $\mathrm{d}=0.07,95 \% \mathrm{CI} 0.05,0.09)$ among recipients." We show that once publication bias is properly accounted for, this effect is depending on the outcome measure - either greatly reduced or completely diminished.

McGuire and colleagues ${ }^{1}$ test for publication bias using Egger regression and $p$-curve. Neither the Egger regression nor the $p$-curve shows evidence for publication bias, and they conclude, "In general, there appears little evidence of publication bias or cherry-picking of results." However, both Egger regression and $p$-curve were shown to perform poorly under high heterogeneity ${ }^{2,3,4,5,6,7}$.

We reanalyse McGuire et al.'s ${ }^{1}$ (2022) results using a novel publication bias adjustment method: robust Bayesian meta-analysis (RoBMA) ${ }^{4}$. RoBMA contains different types of models that emerge from competing assumptions about the publication process. First, RoBMA contains models based on the relationship of effect sizes and standard errors (PET-PEESE) ${ }^{8}$. Second, RoBMA contains different models based on selection for statistical significance ${ }^{9,10}$. These selection models are further split into six selection models with step weight functions at different $p$-value intervals (see Bartoš and colleagues $^{9}$ for technical details). RoBMA then uses Bayesian model-averaging such that inference is impacted most strongly by those models that predicted the data best ${ }^{10}$. In other words, the individual models are combined according to their posterior model probabilities into the RoBMA ensemble.

By simultaneously applying an ensemble of models, RoBMA is more robust to model misspecification. In addition, RoBMA has been shown to perform well in simulation studies as well as on empirical tests ${ }^{4,9}$. Furthermore, in RoBMA evidence for the presence as well as the absence of an effect can be quantified using Bayes factors. As a rule of thumb, Bayes factors between 1 and 3 are 
regarded as weak evidence, Bayes factors between 3 and 10 are regarded as moderate evidence, and Bayes factors larger than 10 are regarded as strong evidence ${ }^{12(A p p e n d i x ~ 1)}$. When quantifying evidence for the null, i.e., evidence for the absence of an effect, the Bayes factor is simply inverted (i.e., $\mathrm{BF}_{01}=$ $\left.1 / \mathrm{BF}_{10}\right)$.

Figure 1 shows the results of a publication bias-adjusted reanalysis using all studies; Table 1 shows the results for all studies and after omitting studies with high risk of bias (based on qualitative coding by McGuire and colleagues ${ }^{1}$ ). Little evidence for an overall impact of cash transfers is apparent. For instance, there is a smidgen of evidence against the presence of a small overall effect (i.e., $\mathrm{BF}_{01}=$ 1.46; posterior mean $\delta=0.03$ ). Furthermore, the evidence of impact of cash transfers by different outcome, study, and transfer types is indecisive and mixed. Specifically, there is moderate evidence against the effect of cash transfers on subjective well being, $\mathrm{BF}_{01}=4.62$, and moderate evidence in favour of the effect on mental health, $\mathrm{BF}_{10}=3.15$. As expected, the evidence against the overall impact and subjective well being fluctuates across a wide range of robustness checks, but it never provides more than weak evidence in support of a small effect. Similar results hold for the mostly positive evidence in favour of the impact on mental health (see Supplementary Materials for details). Evidence in favour of publication bias is moderate and strong for both the overall impact and the subjective well-being outcome, whereas it is mixed and weak for the mental health outcomes.

Application of RoBMA shows that whereas the 84 randomised controlled trials - the gold standard of evidence $^{13}$ - yield no evidence for an effect $\left(\mathrm{BF}_{01}=1.41\right)$, the 28 quasi-experimental designs do yield strong evidence $\left(\mathrm{BF}_{10}=13.07\right)$. However, these positive results appear to be fragile, as the exclusion of the 12 studies with high risk of bias reverses the direction of the evidence $\left(\mathrm{BF}_{01}=2.93\right)$. With respect to transfer type, there is slightly stronger evidence of absence for unconditional cash transfers $\left(\mathrm{BF}_{01}=3.06\right)$ than for conditional cash transfers $\left(\mathrm{BF}_{01}=1.21\right)$, even though this finding is not robust across our sensitivity analyses.

Our reanalysis finds that the evidence for cash transfers on subjective well-being and mental health is at best scant and mixed. Across all model specifications, we robustly find no evidence for an overall effect nor evidence in favour of an increase in subjective well being. The evidence in favour of the effect on mental health depends on model specification. Evidence in the other categories is also sensitive to model specification; however, none of the categories shows robust evidence across all model specifications. Furthermore, all effect sizes reported by McGuire and colleagues ${ }^{1}$ and our reanalysis are quite small, smaller than what might reasonably be regarded as the 'smallest effect size of interest.' The uncertain evidence in regards to the presence of the effects and the clear evidence of publication bias shows that more research is needed, ideally in the form of randomised control trials that are publication bias resistant, such as registered reports ${ }^{14}$. Our analysis suggests that if the effect does exist, it is so small that the sample sizes needed to study may be large - almost 17,500 participants per group of a two-sample $t$-test to achieve $80 \%$ power for detecting effect size of Cohen's $\delta=0.03$. 


\section{Figure 1}

Correcting for Publication Bias Suggests Mixed Evidence of Cash Transfers

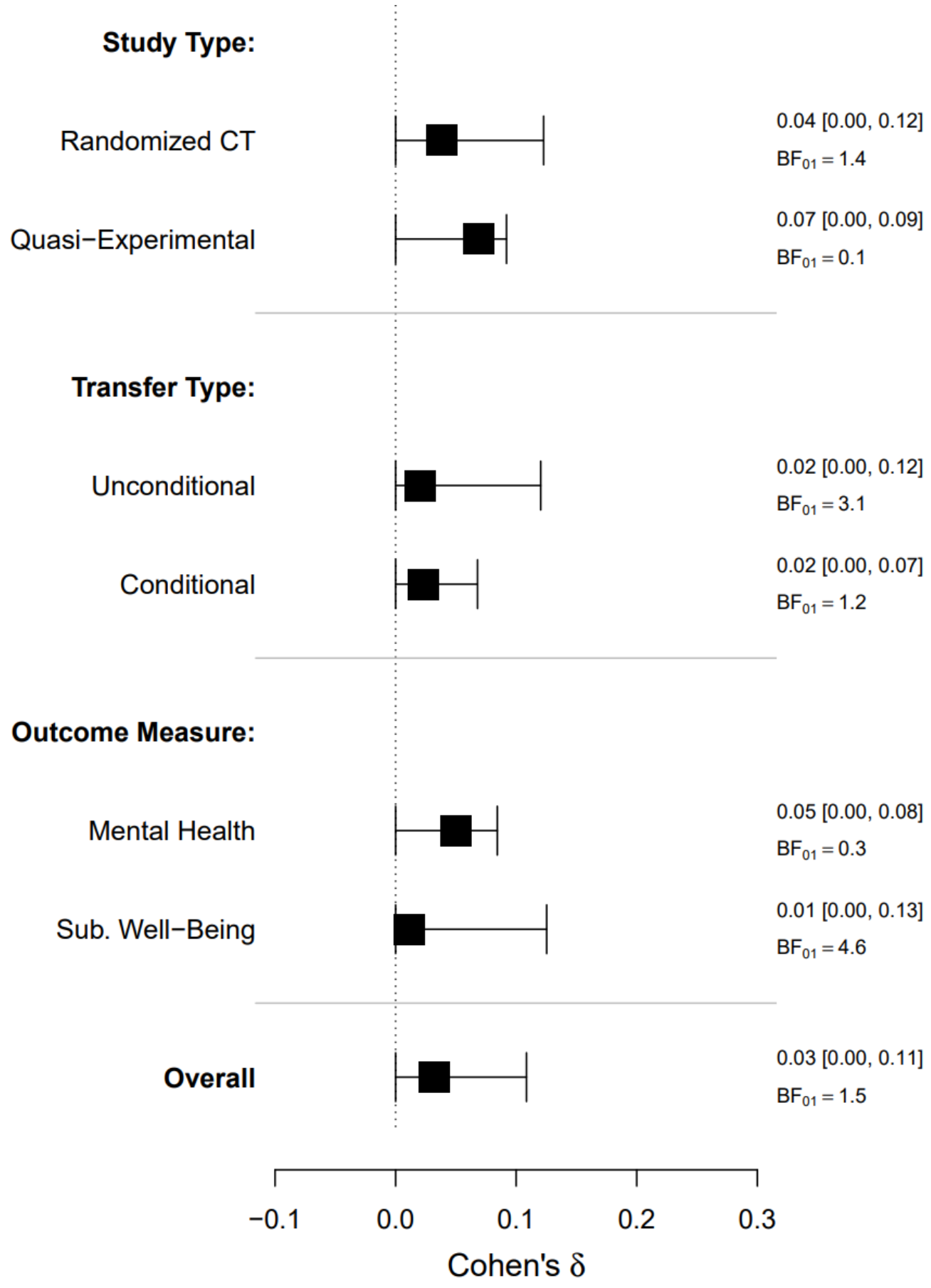

Note. RoBMAPSMA model-averaged posterior mean effect size estimates with $95 \%$ credible intervals and Bayes factors for the absence of the effect for the combined sample or split by either the domain or intervention category (ignoring the clustering of standard errors). $\mathrm{BF}_{01}$ quantifies evidence for the null hypothesis. $\mathrm{BF}_{01}$ larger than 1 corresponds to evidence in favour of the null hypothesis and $\mathrm{BF}_{01}$ lower than 1 corresponds to evidence in favour of the alternative hypothesis (evidence for the alternative hypothesis can be obtained by inverting the Bayes factor; $\left.\mathrm{BF}_{10}=1 / \mathrm{BF}_{01}\right)$. As a rule of thumb, Bayes factors between 3 and 10 indicate moderate evidence and Bayes factors larger than 10 indicate strong evidence. 


\section{Table 1}

Comparison of Unadjusted and Adjusted Effect Size Estimates for All Studies and for Subsets of Studies Based on Different Study, Outcome, and Transfer Types

$$
\text { Random-Effects RoBMAPSMA RoBMAPSMA (Low Bias) }
$$

\begin{tabular}{llll}
\hline Combined & $0.09[0.07,0.12]$ & $0.03[0.00,0.11]$ & $0.03[0.00,0.11]$ \\
& $\mathrm{t}(40)=9.39$ & $\mathrm{BF}_{01}=1.46$ & $\mathrm{BF}_{01}=2.18$
\end{tabular}

Study Type:

\begin{tabular}{|c|c|c|c|}
\hline $\begin{array}{l}\text { Randomised } \\
\text { Control Trial }\end{array}$ & $\begin{array}{l}0.11[0.08,0.14] \\
\mathrm{t}(22)=7.11\end{array}$ & $\begin{array}{l}0.04[0.00,0.12] \\
\mathrm{BF}_{01}=1.41\end{array}$ & $\begin{array}{l}0.07[0.00,0.13] \\
\mathrm{BF}_{01}=0.54\end{array}$ \\
\hline $\begin{array}{l}\text { Quasi-Experimental } \\
\text { Study }\end{array}$ & $\begin{array}{l}0.08[0.05,0.10] \\
\mathrm{t}(17)=7.31\end{array}$ & $\begin{array}{l}0.07[0.00,0.09] \\
\mathrm{BF}_{01}=0.08\end{array}$ & $\begin{array}{l}0.01[0.00,0.07] \\
\mathrm{BF}_{01}=2.93\end{array}$ \\
\hline \multicolumn{4}{|l|}{ Outcome Type: } \\
\hline Mental Health & $\begin{array}{l}0.07[0.05,0.09] \\
\mathrm{t}(28)=7.40\end{array}$ & $\begin{array}{l}0.05[0.00,0.08] \\
\mathrm{BF}_{01}=0.32\end{array}$ & $\begin{array}{l}0.04[0.00,0.09] \\
\mathrm{BF}_{01}=0.51\end{array}$ \\
\hline $\begin{array}{l}\text { Self-Reported } \\
\text { Well Being }\end{array}$ & $\begin{array}{l}0.13[0.09,0.17] \\
\mathrm{t}(24)=6.55\end{array}$ & $\begin{array}{l}0.01[0.00,0.13] \\
\mathrm{BF}_{01}=4.62\end{array}$ & $\begin{array}{l}0.03[0.00,0.16] \\
\mathrm{BF}_{01}=2.09\end{array}$ \\
\hline \multicolumn{4}{|l|}{ Transfer Type: } \\
\hline Unconditional & $\begin{array}{l}0.11[0.09,0.13] \\
\mathrm{t}(27)=9.42\end{array}$ & $\begin{array}{l}0.02[0.00,0.12] \\
\mathrm{BF}_{01}=3.06\end{array}$ & $\begin{array}{l}0.05[0.00,0.14] \\
\mathrm{BF}_{01}=1.13\end{array}$ \\
\hline Conditional & $\begin{array}{l}0.05[0.03,0.08] \\
\mathrm{t}(13)=5.48\end{array}$ & $\begin{array}{l}0.02[0.00,0.07] \\
\mathrm{BF}_{01}=1.21\end{array}$ & $\begin{array}{l}0.03[0.00,0.07] \\
\mathrm{BF}_{01}=0.92\end{array}$ \\
\hline
\end{tabular}

Note. Random-effects meta-analysis estimates with $95 \%$ confidence interval based on clustered standard errors, all $p$-values $<0.001$. RoBMAPSMA model-averaged posterior mean effect size estimates with 95\% credible intervals and Bayes factor for the presence of the effect using either all estimates or studies with low risk of bias. Results differ slightly from the moderator analysis presented in the article because we analysed each subfield separately to allow (a) the testing for the presence of the effect in each category/domain in the Bayesian framework and (b) publication bias to operate differently in different subdomains.

\section{Data \& Materials}

Data and analysis script is available at https://osf.io/6nj8p/.

\section{Acknowledgements}

We thank McGuire and colleagues for sharing well-documented data and code.

\section{Competing interests}

MM is making a small monthly donation to the GiveWell Maximum Impact Fund, some of which is distributed to the cash transfer charity GiveDirectly.

\section{Author Contribution}


FB and MM analysed the data and wrote the first draft of the manuscript, all authors edited and approved the final version of the manuscript.

\section{References}

1. McGuire, J., Kaiser, C. \& Bach-Mortensen, A.M. (2022). A systematic review and metaanalysis of the impact of cash transfers on subjective well-being and mental health in lowand middle-income countries. Nature Human Behaviour, https://doi.org/10.1038/s41562-02101252-Z

2. Brunner, J., \& Schimmack, U. (2020). Estimating population mean power under conditions of heterogeneity and selection for significance. Meta-Psychology, 4. https://doi.org/10.15626/MP.2018.874

3. Carter, E. C., Schönbrodt, F. D., Gervais, W. M., \& Hilgard, J. (2019). Correcting for bias in psychology: A comparison of meta-analytic methods. Advances in Methods and Practices in Psychological Science, 2(2), 115-144. https://doi.org/10.1177/2515245919847196

4. Maier, M., Bartoš, F., \& Wagenmakers, E. J. (in press). Robust Bayesian meta-analysis: Addressing publication bias with model-averaging. Psychological Methods. https://doi.org/10.31234/osf.io/u4cns

5. McShane, B. B., Böckenholt, U., \& Hansen, K. T. (2016). Adjusting for publication bias in meta-analysis: An evaluation of selection methods and some cautionary notes. Perspectives on Psychological Science, 11(5), 730-749. https://doi.org/10.1177/1745691616662243

6. Renkewitz, F., \& Keiner, M. (2019). How to detect publication bias in psychological research. Zeitschrift für Psychologie. 4(227), 261-279. https://doi.org/10.1027/2151-2604/a000386

7. Stanley, T.D., Doucouliagos H., Ioannidis, J.P.A., \& Carter, E. (2021). Detecting publication selection bias through excess statistical significance. Research Synthesis Methods, 12: 776795. https://doi.org/10.1002/jrsm.1512 .

8. Stanley, T. D., \& Doucouliagos, H. (2014). Meta-regression approximations to reduce publication selection bias. Research Synthesis Methods, 5(1), 60-78. https://doi.org/10.1002/jrsm.1095

9. Bartoš, F., Maier, M., Wagenmakers, E., Doucouliagos, H., \& Stanley, T. D. (2021). No need to choose: Robust Bayesian meta-analysis with competing publication bias adjustment methods. PsyArXiv. https://doi.org/10.31234/osf.io/kvsp7

10. Vevea, J. L., \& Hedges, L. V. (1995). A general linear model for estimating effect size in the presence of publication bias. Psychometrika, 60(3), 419-435. https://doi.org/10.1007/BF02294384

11. Hoeting, J. A., Madigan, D., Raftery, A. E., \& Volinsky, C. T. (1999). Bayesian model averaging: a tutorial. Statistical Science, 14(4), 382-417. https://doi.org/10.1214/ss/1009212519

12. Jeffreys, H. (1939). Theory of probability (1 st ed.). Oxford, UK, Oxford University Press.

13. Webber, S., \& Prouse, C. (2018). The new gold standard: The rise of randomized control trials and experimental development. Economic Geography, 94(2), 166-187. https://doi.org/10.1080/00130095.2017.1392235

14. Chambers, C. D. (2013). Registered reports: A new publishing initiative at Cortex. Cortex, 49(3), 609-610. https://doi.org/10.1016/j.cortex.2012.12.016 


\section{Supplementary Materials}

We further analysed the data with an informed prior distribution, $\delta \sim \operatorname{Normal}\left(0,0.30^{2}\right)$, which concentrates most of the prior on small effects. Those results should provide the highest evidence in the favour of the effect (Table A1).

Since publication bias adjustment methods cannot directly accommodate the three-level meta-analytic structure, i.e., multiple estimates obtained from the same study; we also analysed the data using only the most precise estimates. Selecting the most precise estimate from each study mitigatesthe dependency between estimates, however, it discards a substantial amount of information. Furthermore, some authors argue that the PET-PEESE publication adjustment correction might be driven by small study effects and overcorrects for the publication bias. Therefore, we also re-analysed the data with restricted version of RoBMA that only adjusts for publication bias operating on $p$-values, i.e., only using selection models (Table A2).

\section{Table A1}

Evaluating the evidence for the absence of the effect of cash transfers with RoBMAPSMA under an informed alternative hypothesis specifying small standardised effects sizes, $\delta \sim \operatorname{Normal}\left(0,0.30^{2}\right)$.

$$
\text { Complete Sample Low Risk of Bias Most Precise }
$$
Combined
$\mathrm{BF}_{01}=0.45$
$\mathrm{BF}_{01}=0.48$
$\mathrm{BF}_{01}=2.95$

Study Type:

\begin{tabular}{|c|c|c|c|}
\hline $\begin{array}{l}\text { Randomised } \\
\text { Control Trial }\end{array}$ & $\mathrm{BF}_{01}=0.44$ & $\mathrm{BF}_{01}=0.17$ & $\mathrm{BF}_{01}=1.95$ \\
\hline $\begin{array}{l}\text { Quasi-Experimental } \\
\text { Study }\end{array}$ & $\mathrm{BF}_{01}=0.02$ & $\mathrm{BF}_{01}=0.07$ & $\mathrm{BF}_{01}=0.09$ \\
\hline \multicolumn{4}{|l|}{ Outcome Type: } \\
\hline Mental Health & $\mathrm{BF}_{01}=0.10$ & $\mathrm{BF}_{01}=0.11$ & $\mathrm{BF}_{01}=0.43$ \\
\hline $\begin{array}{l}\text { Self-Reported } \\
\text { Well Being }\end{array}$ & $\mathrm{BF}_{01}=1.42$ & $\mathrm{BF}_{01}=0.65$ & $\mathrm{BF}_{01}=2.82$ \\
\hline \multicolumn{4}{|l|}{ Transfer Type: } \\
\hline Unconditional & $\mathrm{BF}_{01}=0.96$ & $\mathrm{BF}_{01}=0.30$ & $\mathrm{BF}_{01}=3.70$ \\
\hline Conditional & $\mathrm{BF}_{01}=0.37$ & $\mathrm{BF}_{01}=0.18$ & $\mathrm{BF}_{01}=1.64$ \\
\hline
\end{tabular}




\section{Table A2}

Evaluating the evidence for the presence vs absence of the effect with only the selection models publication bias adjustment part of RoBMA.

$$
\text { Complete Sample } \quad \text { Low Risk of Bias } \quad \text { Most Precise }
$$

\begin{tabular}{llll}
\hline Combined & $0.02[0.00,0.11]$ & $0.02[0.00,0.11]$ & $0.00[0.00,0.06]$ \\
& $\mathrm{BF}_{01}=2.30$ & $\mathrm{BF}_{01}=3.57$ & $\mathrm{BF}_{01}=12.11$
\end{tabular}

Study Type:

\begin{tabular}{llll}
\hline $\begin{array}{l}\text { Randomised } \\
\text { Control Trial }\end{array}$ & $0.02[0.00,0.12]$ & $\begin{array}{l}0.05[0.00,0.13] \\
\mathrm{BF}_{01}=2.54\end{array}$ & $\begin{array}{l}0.00[-0.00,0.09] \\
\mathrm{BF}_{01}=1.06\end{array}$ \\
$\begin{array}{l}\text { Quasi-Experimental } \\
\text { Study }\end{array}$ & $0.07[0.00,0.09]$ & $0.05[0.00,0.08]$ & $0.05[0.00,0.08]$ \\
Outcome Type: & $\mathrm{BF}_{01}=0.08$ & $\mathrm{BF}_{01}=0.14$ & $\mathrm{BF}_{01}=0.32$ \\
\hline Mental Health & $0.04[0.00,0.08]$ & $0.03[0.00,0.08]$ & $0.02[0.00,0.08]$ \\
& $\mathrm{BF}_{01}=0.58$ & $\mathrm{BF}_{01}=0.94$ & $\mathrm{BF}_{01}=2.31$ \\
Self-Reported & $0.01[-0.01,0.11]$ & $0.02[0.00,0.16]$ & $-0.01[-0.17,0.03]$ \\
Well Being & $\mathrm{BF}_{01}=6.69$ & $\mathrm{BF}_{01}=3.52$ & $\mathrm{BF} 01=8.35$ \\
Transfer Type: & & & \\
\hline Unconditional & $0.01[0.00,0.12]$ & $0.03[0.00,0.13]$ & $-0.00[-0.05,0.03]$ \\
& $\mathrm{BF}_{01}=4.57$ & $\mathrm{BF}_{01}=2.08$ & $\mathrm{BF}_{01}=12.12$ \\
Conditional & $0.05[0.00,0.07]$ & $0.04[0.00,0.07]$ & $0.01[0.00,0.06]$ \\
& $\mathrm{BF}_{01}=0.07$ & $\mathrm{BF}_{01}=0.17$ & $\mathrm{BF}_{01}=3.04$ \\
\hline
\end{tabular}

